\title{
TÂNATOS E O MITO DA ESCRITURA: MORTE E CRIAÇÃO NOS ESCRITOS DE ALBERT CAMUS
}

\author{
Samara Fernanda A. O. de Lócio e Silva Geske ${ }^{1}$
}

RESUMO: Tomando como ponto de partida o aniversário de 50 anos da morte de Albert Camus (19131960), o objetivo desse artigo é analisar o tema da morte em seus escritos. Ela é revelada ao escritor muito cedo através da experiência da doença, mas ao contrário de conduzi-lo ao pessimismo e à angústia, a proximidade da morte exaspera nele o amor à vida e a urgência da criação. Sua obra revela-se como um embate entre Tânatos, a morte, e Sísifo, representando o amor à vida e ao mundo. Dessa forma, analisamos como a experiência da morte e da doença aparece em seus primeiros escritos e como as imagens de vida e morte se alternam em seus primeiros ensaios. A morte está também estritamente ligada à revelação do Absurdo em Le Mythe de Sisyphe e se torna o tema central das suas narrativas, principalmente em L'Étranger. A morte, por fim, interrompe a sua escritura, deixando inacabado o romance cujo ponto de partida fora a morte de seu pai morto na guerra.

PALAVRAS-CHAVE: Morte, Escritura, Mito, Sísifo.

\begin{abstract}
Starting from the Anniversary of 50 years of Albert Camus' death, the purpose of this article is to analyze the topic of death in his writings. The death is revealed to the writer too early through the experience of sickness, but instead of leading to pessimism and the angst, the proximity of death provokes in him the love of the life and the urgency for creation. His work reveals itself as a collision between Thanatos, the Death, and Sisyphus, representing the love of the life and the earth. Thus, we analyze how the experience of death and the sickness appears in his first writings and how the images of life and death interchange into his first essays. The death is also linked to the revelation of Absurd in Le Mythe de Sisyphe and turns into the central topic of his narratives, mainly in L'Etranger. At last, the death interrupts his writings, leaving unfinished the novel that the starting point is the death of his father on the war.
\end{abstract}

KEYWORDS: Death, Writing, Myth, Sisyphus.

\footnotetext{
${ }^{1}$ GESKE, Samara Fernanda A. O. de Lócio e Silva. Mestranda em Literatura Francesa junto à área de Estudos Linguísticos, Literários e Tradutológicos em Francês (FFLCH-USP). E-mail: samaralocio@gmail.com
} 


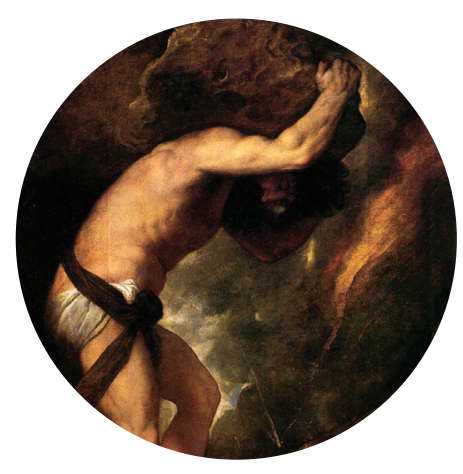

Sísifo - detalhe, óleo sobre tela de Tiziano Vecellio

"Les mythes sont faits pour que l'imagination les anime." Le Mythe de Sisyphe, Albert Camus.

\section{INTRODUÇÃO}



onta-nos a mitologia grega que Tânatos, o deus da morte, era irmão de Hipnos, o deus do sono e filho de Nyx, a deusa da noite. Conta-nos também que certo jovem astucioso chamado Sísifo, o primeiro rei de Corinto, derrotou e aprisionou Tânatos quando este veio buscá-lo. Acorrentando a morte, Sísifo deu imortalidade aos seres humanos. Irritados, Hades, o deus dos mortos e Ares, o deus da guerra, libertaram Tânatos e ordenaram que Sísifo fosse levado aos infernos.

Antes de partir, Sísifo pediu a sua mulher que não enterrasse seu corpo, assim, chegando ao inferno, ele pôde reclamar a Hades sobre a falta de respeito de sua esposa e foi-lhe concedido mais um dia na terra para puni-la. Ele voltou à terra, "e tendo visto novamente este mundo, experimentado a água e o sol, as pedras quentes e o mar, ele não quis retornar para a sombra infernal", retomou o seu corpo e fugiu. Enganara a morte mais uma vez.

Mas Sísifo foi condenado novamente: por toda a eternidade deveria rolar uma pedra de mármore até o cume de uma montanha, para que de lá ela rolasse até embaixo, e seu trabalho recomeçasse.

Para Camus, Sísifo é o herói absurdo por excelência, tanto por seu desprezo pelos deuses e seu ódio da morte quanto por sua paixão pela vida. Os mitos sempre foram muito caros ao escritor, eles estão presentes tanto em sua reflexão filosófica quanto em sua criação literária. ${ }^{2}$ Camus

\footnotetext{
2 “Le monde où je suis plus à l’aise: le mythe grec." (CAMUS, 1962, p. 317). 
nunca se considerou um filósofo, antes ele se considerava "um artista que cria mitos na medida de sua paixão e de sua angústia" (CAMUS, 1962, p. 325). Sua obra foi escrita, como ele próprio afirma, a partir de figuras mitológicas: Sísifo encarna o absurdo, Prometeu, a revolta e Nêmesis, a moderação. $^{3}$

Este trabalho propõe assim um mito da escritura camusiana: o embate entre Sísifo e Tânatos, entre os prazeres deste mundo e a certeza da morte que perpassa toda a obra do escritor.

\section{TÂNATOS ENCONTRA CAMUS: O COMEÇO DA ESCRITURA}

A morte é a destruição do corpo, em certo sentido nós a experimentamos tanto na velhice quanto na doença. A vida de Camus foi dominada pela ideia da morte eminente - "a sensação da morte que me é familiar agora... Pressentir a morte vendo simplesmente um lenço cheio de sangue" (CAMUS, 1965, p. 89) - revelada pela tuberculose por volta de 1930

Ele tem 17 anos, e uma afecção grave no pulmão direito. O hospital lhe causa repulsa, assim como as radioscopias e os pneumotórax a cada quinze dias. Jovem, confrontado com a morte, ele descobre o Absurdo: "Adolescente. Sua força de vida. Sua fé na vida. Mas ele cospe sangue. A vida será isso, o hospital, a morte, a solidão, esta absurdidade. Daí a dispersão. E ele no fundo: não, não, a vida é outra coisa" (CAMUS, 2008, p. 360). Primeiro encontro entre Tânatos e Sísifo: descobrir-se mortal e amar a vida.

A reação da família também faz parte desta abertura, ao mesmo tempo, ao absurdo e à escritura. O Absurdo é revelado ao menino pelo silêncio da mãe e por sua indiferença em relação à doença. ${ }^{4}$ Por esse motivo, o menino é levado para a casa do tio mais abastado, onde pode receber melhores cuidados. Lá ele descobre uma rica biblioteca. Um dia, o tio oferece ao menino um pequeno livro dizendo: "Isto te interessará." Esse livro era Les Nourritures Terrestres, de André Gide. Essa leitura será fundamental na fase em que Camus começa a se abrir para o "mundo da criação". Nesse momento de sua vida, o jovem lê avidamente porque "uma feliz doença havia me separado das minhas praias e meus prazeres" (CAMUS, 2000, p. 1118).

Seguem-se a estada em sanatórios e o aprendizado trazido tanto pela doença quanto pela solidão, ela é ao mesmo tempo ruptura dolorosa com a infância e exílio com relação à vida anterior naquilo em que ela o separa dos "outros"

Il avait dix-sept ans. Un de ses oncles se chargea de le soigner. On le mit pourtant à l'hôpital. Il ne put rester plus d'une nuit. Mais il avait eu le temps, dans cette nuit de complète insomnie, dans les toux, les crachements et les mauvaises odeurs, de sentir jusqu’à quel point il était retranché du monde vivant où les « autres » sont en bonne santé (CAMUS, 2000, p. 86).

\footnotetext{
3 “I. Le Mythe de Sisyphe (absurde). - II. Le Mythe de Prométhée (révolte). - III. Le Mythe de Némésis.” (CAMUS, 1962, p. 328).

4 "Elle n'ignorait pourtant pas la gravité de son mal mais elle promenait ainsi sa surprenante indifférence." (CAMUS, 2000, p. 1214).

${ }^{5}$ Sobre a separação dos outros ver Carnets I p.19: “Ce qui nous sauve de nos pires douleurs, c'est ce sentiment d'être abandonné et seul, mais pas assez seul cependant pour que « les autres » ne nous « considèrent » pas dans notre malheur. C'est dans ce sens que nos minutes de bonheur sont parfois celles où le sentiment de notre abandon nous gonfle et nous soulève dans une tristesse sans fin" (Maio de 1935).
} 
A solidão imposta pela doença, no entanto, será profícua, ela permitirá que Camus comece a escrever:

Aujourd'hui, je me sens libre à l'égard de mon passé et de ce que j’ai perdu. [...] Aller jusqu'au bout, c'est savoir garder son secret. J'ai souffert d'être seul, mais pour avoir gardé mon secret, j’ai la souffrance d'être seul. Et aujourd'hui, je ne connais pas de plus grande gloire que de vivre seul et ignoré. Écrire, ma joie profonde! (CAMUS, 1962, p. 75-77).

Já sendo um escritor consagrado, Camus é questionado por um jornalista acerca do início de sua carreira. Ele responde que o nascimento do desejo de ser escritor apareceu a ele justamente nesta época decisiva: em 1930 ele encontrava ao mesmo tempo a doença, a filosofia e o mundo da criação. ${ }^{6}$

Em seus primeiros textos a presença dos temas da doença e da morte será constante, como veremos. Assim como Manuel Bandeira ${ }^{7}$ que, descobrindo-se tuberculoso, não pôde seguir sua carreira como arquiteto, a doença também mudou o rumo da vida de Camus. Por causa da tuberculose, ele não pôde obter aprovação nos exames médicos da agrégation e seguir a carreira de professor. Camus, no entanto, nunca se afastará da Filosofia, mas este distanciamento do mundo acadêmico permitirá que ele transite com liberdade entre a reflexão filosófica e o universo da criação literária. ${ }^{8}$ Essa via dupla será um dos aspectos mais expressivos de sua escritura.

Camus experimentara por sua doença uma indiferença, até o momento em que publica seu primeiro livro. O medo da morte é agora o medo de calar a voz do escritor:

J'ai tant de choses à dire. Je ne comprenais pas ce que vous me disiez souvent: que quelque fois une peur vous prenait d'être écrasé dans la rue sans avoir eu le temps de manifester. Je comprends maintenant, parce que j’ai quelque chose à manifester. Je travaille beaucoup. Je veux vivre pour ça et c'est l'essentiel (Carta a Jean de Maisonseul - CAMUS, 2000, p. 97-98).

A doença ensina a Camus não apenas uma lição de vida, mas também uma lição de literatura.

\footnotetext{
6 “À quelle époque de votre vie avez-vous nettement pris conscience de votre vocation d'écrivain? Vocation n'est pas le bon mot. J'ai eu envie d'être écrivain vers dix-sept ans, et, en même temps, j’ai su, obscurément, que je le serais.” (Respostas a Jean-Claude Brisville, CAMUS, 2000, p. 1919).

${ }^{7}$ Camus conhece Manuel Bandeira na viagem que faz ao Brasil em 1959. CAMUS, Albert Diário de Viagem Rio de Janeiro: Record, 1997.

${ }^{8}$ Para apresentar-se a agrégation, o candidato deveria escrever um memorial e um texto de mais ou menos 120 páginas, chamado DES (Diplôme d'Études Supérieures). O trabalho de Camus intitulava-se "Métaphysique chrétienne et néoplatonisme, Plotin et Saint Augustin". Seus avaliadores notaram rapidamente que este trabalho acadêmico guarda muitas semelhanças com um ensaio literário, aqui e lá aparecem expressões que se afastam do academicismo universitário. Do memorial redigido por Camus seu avaliador nota que ele seria um ótimo candidato, mas julga que este prova mais suas qualidades literárias (TODD, 2000, pp. 136-147).
} 
A doença ensina uma lição, em primeiro lugar, pois cria um aprendizado para a morte:

Rien de plus méprisable à cet égard que la maladie. C'est un remède contre la mort. Elle y prépare. Elle crée un apprentissage dont le premier stade est l'attendrissement sur soi-même. Elle appuie l'homme dans son grand effort qui est de se dérober à la certitude de mourir tout entier (CAMUS, 2006, p. 114).

Os primeiros textos que Camus escreve datam de 1933 e exploram o tema da doença e da morte9: "Voilà! Elle est morte...", "Perte de l'être aimé...", “Accepter la vie..." e "L'hôpital du quartier pauvre". ${ }^{10}$ Esses textos serão os primeiros a explorar a ideia deste aprendizado, que depois não cessará de aparecer nos escritos camusianos.

O primeiro texto tem um cunho mais narrativo, o narrador em primeira pessoa nos apresenta a situação: sua amada está morta. Ele registra com estranhamento que no dia anterior ela estava viva, mexia-se e até falava um pouco, mesmo estando doente. O segundo e o terceiro texto possuem um aspecto mais filosófico, trata-se de refletir sobre a perda do ser amado, sobre a aceitação da dor e da morte, enfim, que não existe nenhuma transcendência possível. Esses primeiros textos nos mostram a maneira como o escritor continuará a escrever, sempre entre a expressão literária e a reflexão filosófica. ${ }^{11}$

O terceiro texto "L'hôpital du quartier pauvre" é sem dúvida uma evocação de origem biográfica, trata-se possivelmente da estadia de Camus no hospital Mustapha. Toda a ação se resume à saída matinal de um grupo de tuberculosos para tomar sol no jardim. O narrador, com ironia, descreve a saída matinal dos doentes como uma revoada de crianças que saem da escola, entre risos e tosse. Também ironicamente, o único assunto da conversação entre aqueles homens é a doença e a morte dos tuberculosos. Eles repetem frases para tentar colorir de esperança o futuro ${ }^{12}$ : "A tuberculose é a única doença que sabemos que podemos ser curados. É preciso somente tempo" (CAMUS, 2006, p. 75). Essas conversas resumiam a vida daqueles homens, que "só temiam a própria morte, e, ao contrário, desejavam a morte de todo o mundo, aquela que está em um futuro distante" (CAMUS, 2006, p. 75).

\footnotetext{
${ }^{9}$ Em 1932, Camus escreve para a revista Sud, mas trata-se de ensaios sobre alguns autores como Verlaine, Jean Rictus e Bergson. De outubro de 1933 datam os textos que mais se aproximam da forma da narrativa.

${ }^{10}$ Cf. VIALLANEIX, Alain Écrits de jeunesse d'Albert Camus Paris: NRF, Gallimard, 1973.

11 “[...] j'avais un plan précis quand j’ai commencé mon oeuvre: je voulais d'abord exprimer la négation. Sous trois formes. Romanesque: ce fut L'Étranger. Dramatique: Caligula, Le Malentendu. Idéologique: Le Mythe de Sisyphe. [...] Je prévoyais le positif sous les trois formes encore. Romanesque: La Peste. Dramatique: L'état de siège et Les Justes. Idéologique: L'Homme revolté. J'entrevoyais déjà une troisième couche, autour du thème de l'amour" (CAMUS, 2000, p. 1610).

${ }^{12}$ A ironia contida nesta esperança de cura também foi explorada num texto posterior, guardando também muitos traços da experiência da doença vivida por Camus: “On peut être là, couché un jour, s'entendre dire: 'Vous êtes fort et je vous dois d'être sincère: je peux vous dire que vous allez mourir.' [...] Mais les hommes meurent malgré eux, malgré leurs décors. On leur dit: 'Quand tu seras guéri..., et ils meurent. Je ne veux pas de cela. Car il y a des jours où la nature ment, il y a des jours où elle dit vrai'” (CAMUS, 2006, p. 115).
} 


\section{SÍSIFO ENGANA TÂNATOS: AS ALEGRIAS DESTA TERRA}

"Les rappels, les colères et les avertissements n’y firent rien. Bien des années encore, il vécut devant la courbe du golf, la mer éclatante et les sourires de

la terre."

Le Mythe de Sisyphe, Albert Camus.

Ainda jovem Camus faz outro aprendizado diverso daquele ensinado por sua doença. Esse ensino foi oferecido a ele pela terra onde nasceu e se criou, como revelam as notas dos Carnets durante os anos de 1935 e 1936: "O livro se abre em uma página que amamos. Hoje ela [a angústia] é insignificante na presença do livro do mundo" (CAMUS, 1962, p. 22).

Em Alger, para quem é jovem e cheio de vida, tudo se torna refúgio e pretexto para regozijar-se: a baia, o sol, as flores, as estações e as moças. Para os que estão doentes ${ }^{13}$ ou envelheceram não há nada para se apegar: "Tudo aqui respira o horror de morrer em país que convida para a vida” (CAMUS, 2006, p. 123). Assim, nos dois primeiros livros de ensaios que Camus publica na Argélia, as imagens de morte estarão estritamente ligadas às imagens de vida.

L'Envers et L'Endroit (1937), título da primeira reunião de ensaios publicada por Camus nos revela exatamente esse traço de sua escritura nesses primeiros anos: a coexistência de elementos contraditórios. Nesses escritos se misturam luz e sombra, felicidade e desgraça, esperança e desespero, vida e morte, enfim, o avesso e o direito do mundo. Entre esses opostos ele se recusa a escolher. ${ }^{14}$ Os críticos, porém, leram nessa obra amargura e pessimismo, no entanto, o escritor responde: "Se eu já não tivesse falado de todo gosto que eu encontro na vida, todo o desejo que eu tenho de mordê-la, se eu já não tivesse dito que a morte e a dor só exasperavam em mim essa ambição de viver, então eu não disse nada" (CAMUS, 2006, p. 97). A morte se torna o centro de seus escritos, exatamente pelo seu contrário: o amor à vida e a esse mundo. O narrador exclama como Sísifo: “Todo meu reino é desse mundo" (CAMUS, 2006, p. 71).

Noces (1938) exalta a comunhão entre o homem e o mundo: "Noces à Tipasa" canta as belezas desta cidade argelina e descreve um dia de comunhão com o mundo. O narrador, como Sísifo, delicia-se mergulhando no mar, ainda perfumado de essências da terra. Em "Le vent à Djémila" mais uma vez o narrador identifica-se com o apego à vida de Sísifo: "Então eu penso: flores, sorrisos, desejos de mulher, e eu compreendo que todo meu horror de morrer está em meu ciúme de viver" (CAMUS, 2006, p. 114). Os ensaios também nos revelam a obsessão do escritor pelos epitáfios gravados nos túmulos, onde são reveladas a resignação diante da morte e a esperança de uma vida futura. Camus se revoltava diante de ambas, a morte não se abriria sobre outra vida, ela é uma porta fechada. O que a natureza nos ensina é que "nesses evangelhos de pedra, de céu e de água, está escrito que nada ressuscita” (CAMUS, 2006, p. 134).

A vida, esta vida, é que se torna um valor.

\footnotetext{
13 "Ma jeunesse me fuit: c'est cela être malade" (CAMUS, 1965, p. 52).

${ }^{14}$ C'est vrai que les pays méditerranéens sont les seuls où je puisse vivre, que j'aime la vie et la lumière; mais c'est aussi vrai que le tragique de l'existence obsède l'homme et que le plus profond de lui-même y reste attaché. Entre cet envers et cet endroit du monde et de moi-même, je me refuse à choisir. Si vous voyez un sourire sur les lèvres désespérées d'un homme, comment séparer celui-ci de celles-là? (CAMUS, 2006, p. 74 - Appendices à L'Envers et L'Endroit [Projet de Préface]).
} 


\section{SÍSIFO É CONDENADO: O ABSURDO}

"Il fallut un arrêt de dieux. Mercure vint saisir l'audacieux au collet et, l'ôtant à ses joies, le ramena de force aux enfers où son rocher était tout prêt." Le Mythe de Sisyphe, Albert Camus.

Schopenhauer escreve que a morte é propriamente o gênio inspirador, ou a musa da filosofia, pelo que Sócrates a definiu como qanatou meleth [preparação para a morte]. Dificilmente se teria filosofado sem ela (2004, p. 59). Em maio de 1936, Camus também prevê "Um ensaio sobre morte e Filosofia" assim como uma "Obra filosófica: a absurdidade" (CAMUS, 1962, p. 40). Ele unirá uma reflexão sobre a morte e o absurdo em seu primeiro ensaio que será escrito entre setembro de 1940 e fevereiro de 1941, quando podemos ler em seus Carnets: "Terminado Sísifo. Os três Absurdos estão terminados" (CAMUS, 1962, p. 224). Trata-se de L'Étranger, Le Mythe de Sisyphe, Caligula e Le Malentendu que ele escreve concomitantemente (CAMUS, 1965, p. 201).

O Absurdo é fundamental para o pensamento de Camus, ele é a "primeira das suas verdades". A morte é uma das primeiras descobertas do absurdo, pelo simples fato de estar vivo o homem está condenado à morte. Ela é absurda, pois está em contradição com o desejo natural de viver do homem: "Esta revolta na carne, é o absurdo" (CAMUS, 2000, p. 228).

Assim, se nossa existência é finita, se tudo caminha para morte, nada mais faz sentido e, portanto, a vida não vale a pena ser vivida. Para Camus, julgar se a vida vale ou não a pena ser vivida é responder a uma questão fundamental da filosofia. É por isso que o tema de seu ensaio é a relação entre o absurdo e o suicídio, na medida em que o suicídio é uma solução ao absurdo.

É precisamente nesse ponto que o mito de Sísifo interessa a Camus. Aqueles que o puniram tinham pensado, com suas razões, que não existe punição mais terrível do que o trabalho inútil e sem esperança. Essa seria também nossa vida: levantar-se, trabalhar, retornar para a casa e isso todos os dias. Um dia somente, o porquê se levantaria. Camus escreve: "o cansaço está no final de uma vida mecânica, mas inaugura ao mesmo tempo um movimento de consciência" (CAMUS, 2000, p. 228). Esse movimento de consciência é precisamente a revelação do absurdo. O homem tem então duas saídas: suicídio ou consciência.

Sísifo encarna o herói absurdo justamente porque é consciente:

Il redescend dans la plaine. C'est pendant ce retour, cette pause, que Sisyphe m’intéresse. [...] Je vois cet homme redescendre d'un pas lourd mais égal vers le tourment dont il ne connaîtra pas la fin. Cette heure qui est comme une respiration et qui revient aussi sûrement que son malheur, cette heure est celle de la conscience. À chacun de ces instants, où il quitte les sommets et s'enfonce peu à peu vers les tanières des dieux, il est supérieur à son destin. Il est plus fort que son rocher (CAMUS, 2006, p. 302).

Sísifo é superior ao seu destino e é nessa medida que ele se torna um homem livre e feliz. Em carta a Gaston Gallimard, Camus previra um título para essa parte do texto: "Sisyphe ou le bonheur aux Enfers” (CAMUS, 2006, p. 320). 
O Absurdo, dessa forma, não direciona Camus para o pessimismo e para morte, antes para a vida e a felicidade:

On ne découvre pas l'absurde sans être tenté, d'écrire quelque manuel du bonheur.. «Eh! quoi, par des voies si étroites...?» Mais il n’y a qu'un monde. Le bonheur et l'absurde sont deux fils de la même terre. Ils sont inséparables (CAMUS, 2006, p. 303).

É por isso que a vida se torna um valor. Imaginar uma outra realidade ou desejar outra vida equivale à resignação. Essa seria a segunda fuga para o absurdo: a esperança.

O cristianismo construirá suas bases sob a esperança, a morte de nenhuma maneira é um fim, ao contrário, é ela quem abre as portas para a vida eterna. Não para o homem absurdo: ele é um exilado, mas ao contrário do senso comum, ele não tem saudades de uma pátria perdida nem a esperança de para lá voltar. Não há a possibilidade de uma transcendência, neste sentido podemos compreender a epígrafe que Camus escolhe para seu ensaio: "Oh minha alma, não aspire à vida imortal, mas esgote o campo do possível” (CAMUS, 2006, p. 217).

\title{
5. A MORTE E O NASCIMENTO DA NARRATIVA
}

Desde 1935, encontramos nos Carnets notas e planos para uma possível narrativa, mas é durante 1937 que elas começam a abundar. Em abril lemos em um plano de trabalho: "Romance - Trabalhar nele” (CAMUS, 1962, p. 47). É também em 1937 que a doença encontra Camus mais uma vez:

\begin{abstract}
Sur le chemin de Paris: cette fièvre qui bat aux temps, l'abandon singulier et soudain du monde et des hommes. Lutter contre son corps. Sur mon banc, dans le vent, vidé et creusé par l'intérieur, je pensais tout le temps à K. Mansfield, à cette longue histoire tendre et douloureuse d'une lutte avec la maladie. Ce qui m’attend dans les Alpes, avec la solitude et l'idée que je serai là pour me soigner, la conscience de ma maladie (CAMUS, 1962, p. 60).
\end{abstract}

A experiência da doença será mais uma vez central para a criação, ela desperta em Camus a urgência de viver e criar. ${ }^{15}$ E é o que Camus fará, entre o verão de 1937 e 1938 ele trabalhará nesse romance, cujo nome lemos pela primeira vez em uma nota de setembro de 1937: La Mort Heureuse. Mais que isso, a doença será central para a narrativa em si: são dois personagens doentes. Um deles é o milionário Zagreus, amputado das duas pernas. Ele ressalta que um corpo doente, enfraquecido está privado da alegria, retomando, assim, a temática desenvolvida nos primeiros ensaios: "E você Mersault, com o seu corpo, o seu único dever é viver e ser feliz" (CAMUS, 2006, p. 1126). Mersault também é acometido por uma doença que contrai possivelmente no dia em que assassina Za-

${ }^{15}$ CAMUS, 1962, p. 67: "Il faut vivre et créer" e CAMUS, 1965, p. 104: “Ne pas oublier: la maladie et sa décrépitude. Il n’y a pas une minute à perdre." 
greus. ${ }^{16} \mathrm{O}$ tempo passa, enquanto Mersault viaja e desfruta do dinheiro que roubou do milionário. Um dia cai de cama pela primeira vez: era a tuberculose. Entre as tosses, o sangue e os tremores ele toma consciência da sua doença. ${ }^{17}$ É bem provável que na origem de "La Mort Consciente" título da segunda parte de La Mort Heureuse exista a reflexão sobre essa doença conscientemente vivida. A consciência da doença se torna, assim, a consciência de uma morte que se aproxima.

Mersault, porém, não deseja morrer como um doente, ele não quer que a doença seja o que tantas vezes é: "uma atenuação e como uma transição para a morte" (CAMUS, 2006, p. 1191). Ao contrário, ele desejava encontrar-se com ela com sua vida plena de sangue e de saúde. Sua febre é confrontada a toda aquela beleza espalhada sobre o mundo e como Sísifo "ele não queria deixar seu gosto e seu ciúme de viver" (CAMUS, 2006, p. 1191).

Ele sofre delírios de febre, mas seu desejo é manter a consciência até o fim e morrer de olhos abertos. Como vimos, essa é uma ideia cara ao pensamento de Camus: a lucidez. ${ }^{18}$ Ela possui alguns sinônimos em seus escritos como "éveil", "clairvoyance", "conscience”. Estar consciente e lúcido diante da morte significa, para Camus, ter uma morte feliz. Daí o título de sua primeira narrativa, ele reflete a consonância entre a felicidade de viver e de morrer $^{19}$, como planejou em uma nota: "Tema: O Universo da morte. Obra trágica. Obra feliz" (CAMUS, 1962, p. 123).

A consciência e a lucidez diante da morte é também uma realidade para o condenado à pena capital, diversas notas para La Mort Heureuse falam da "História do condenado à morte". Patrice, personagem do romance, anota Camus, conta sua história de condenado à morte: "Eu sei que agora eu vou escrever. Eu não falarei de outra coisa a não ser de meu amor de viver" (CAMUS, 1962 , p. 24). A proximidade da morte, tanto a revelada pela doença quanto pela pena capital ${ }^{20}$ sig- $^{-}$ nificam para Camus a urgência de criar, de escrever, de testemunhar seu amor pela vida. ${ }^{21}$

No entanto, no romance, Patrice não será um condenado à pena capital, tampouco escreverá sua história, pois ela será narrada em terceira pessoa. Camus abandona a narrativa. Em junho de 1938, lemos em uma nota: "Reescrever romance" (CAMUS, 1962, p. 112), mas Camus não re-

\footnotetext{
${ }^{16}$ No final do primeiro capítulo, depois que assassina Zagreus, a doença já começa a se anunciar: "En arrivant sur la place, il prit soudain conscience du froid et frissonna sous son léger veston. Il éternua deux fois [...] Un troisième éternuement le secoua, et il sentit comme une frisson de fièvre" (CAMUS, 2006, p. 1107). É interessante notar que esta passagem retoma trechos de "L'hôpital du quartier pauvre" para compor o cenário. Ver de "Du ciel bleu descendaient des millions de petits sourires blancs [...] até "il semblait que la seule tache des hommes fût de vivre et d'être heureux" (CAMUS, 2006, pp. 1107-1108).

${ }^{17}$ Lévi-Valensi destaca a relação entre Mersault e o escritor: "Les malaises de Mersault et la maladie qui finira par l'emporter doivent évidemment beaucoup à ceux qu'a connus Camus” (2006, p. 458).

${ }^{18} \mathrm{O}$ termo aparece em uma das primeiras notas dos Carnets I de maio de 1935, a palavra absurdité está ligada a lucidité (1962, p. 23). A ligação entre a lucidez e o absurdo pode ser melhor compreendida em uma nota de março de 1942: "Parvenu à l'absurde, s'essayant à vivre en conséquence, un homme s'aperçoit toujours que la conscience est la chose du monde la plus difficile à maintenir. Il s'agit de vivre la lucidité dans un monde où la dispersion est la règle" (CAMUS, 1965, p. 19). O que aqui nos interessa é falar da lucidez diante da morte. Ela é também uma realidade para o condenado à morte: "L'évident c'est qu'on va lui couper le cou et pendant qu'il est lucide - pendant même que toute sa lucidité se concentre sur ce fait qu'on va lui couper le cou” (CAMUS, 1962, p. 141).

${ }^{19}$ Sobre este tema ver : "Là était tout son bonheur de vivre et de mourir" (CAMUS, 2006, p. 1194) e "Car lui avait rempli son rôle, avait parfait l'unique devoir de l'homme qui est seulement d'être heureux" (CAMUS, 2000, p. 1195). Ver nos Carnets I: "La mort! A continuer ainsi, je finirais bien par mourir heureux" (CAMUS, 1962, p. 72).

${ }^{20}$ Seguindo o raciocínio de Camus a doença representaria uma pena de morte metafísica (a imposta pela própria certeza da finitude humana), enquanto a pena capital representaria a pena de morte histórica (aquela imposta pelos homens).

${ }^{21}$ Capítulo I. “- Catherine, diz Patrice, eu sei que agora eu vou escrever. História do condenado à morte. Eu me entrego à minha verdadeira função que é escrever” (CAMUS, 1962, p. 25).
} 
escreve La Mort Heureuse ${ }^{22}$, ele escreve L'Étranger.

Nessa passagem, conserva-se a estrutura das duas narrativas, a primeira parte nos narra um assassinato (o de Zagreus e o do árabe). Na segunda narrativa, porém, a natureza tem um papel central: o sol e o mar se tornam quase personagens na cena do assassinato. Aqui se manifesta a indiferença e a opacidade do mundo apresentada como um dos signos do Absurdo em Le Mythe de Sisyphe.

A segunda parte das narrativas dá conta do destino do criminoso, em ambos os casos, a morte. A mudança fundamental é que na primeira a morte se dá pela doença e a na segunda pela condenação. Aqui encontramos o personagem do condenado à morte que narra sua história. A narrativa inicia-se por uma espécie de diário: "Hoje mamãe morreu". ${ }^{23} \mathrm{E}$, ao longo de toda a primeira parte, ele nos narra suas atividades rotineiras como: "Hoje eu trabalhei muito no escritório". A segunda parte da narrativa se assemelha muito às memórias escritas pelo condenado enquanto está preso. Possivelmente ele começa a escrever depois que é condenado à morte, mas ele nunca fala sobre esse momento de escrita. A história se interrompe, possivelmente antes de sua morte, as últimas palavras que ele escreve são: "Para que tudo esteja consumado, para que eu me sinta menos só, me restava apenas desejar que no dia de minha execução houvesse muitos espectadores e que eles me recebessem com gritos de raiva" (CAMUS, 2006, p. 213).

No entanto, as ideias principais de La Mort Heureuse ainda se conservam: a lucidez e a alegria diante da morte. Meursault, quando confrontado pelo capelão, revela-se consciente de sua morte. ${ }^{24} \mathrm{E}$ no final da narrativa, após a revelação do absurdo, sente-se feliz. ${ }^{25}$ Essa felicidade nasce principalmente de uma abertura para a indiferença do mundo:

Je crois que j'ai dormi parce que je me suis réveillé avec des étoiles sur le visage. Des bruits de campagne montaient jusqu’à moi. Des odeurs de nuit, de terre et de sel rafraîchissaient mes tempes. La merveilleuse paix de cet été endormi entrait en moi comme une marée (CAMUS, 2006, p. 212).

Camus vislumbrou a possibilidade de outros títulos para L'Étranger, como deixa registrado em um manuscrito da narrativa, entre eles encontramos "O estrangeiro ou Um homem feliz." Aqui a relação entre o mito de Sísifo e o personagem se estreita: "É preciso imaginar Sísifo feliz". Lemos em Le Mythe de Sisyphe como é necessário também imaginar Meursault feliz diante de sua condenação.

L'Étranger, publicado em 1942 na França, foi a obra que lançou Camus como escritor. A partir de então, a morte não cessou de aparecer em seus escritos, entre os quais podemos citar La Peste, L'Homme Révolté e La Chute.

\footnotetext{
${ }^{22}$ CAMUS, Albert, «La Mort Heureuse», In: Cabiers Albert Camus I, Paris, Gallimard, 1971. Essa narrativa será publicada somente 11 anos após sua morte.

${ }^{23}$ É interessante notar a simetria entre as partes: a narrativa se abre pela morte da mãe e fecha com o assassinato do árabe. Na segunda parte, o personagem é preso por esse crime e julgado por ser indiferente e não ter chorado no enterro da mãe, no final ele é condenado à morte.

24 "Mais j'étais sûr de moi, sûr de tout, plus sûr que lui, sûr de ma vie et de cette mort qui allait venir" (CAMUS, 2006, p. 211).

25 “J'ai senti que j'avais été heureux, et que je l'étais encore” (idem).
} 


\section{TÂNATOS INTERROMPE A ESCRITURA}

Muito antes de sua doença, Tânatos já havia encontrado Camus e transformado sua vida, seu pai morrera na guerra. Camus se torna, assim, um dos órfãos da guerra que se espalhavam por todos os cantos da Argélia, "árabes e franceses, filhos e filhas sem pai, que deveriam aprender a viver sem lições nem herança" (CAMUS, 2008, p. 83).

Camus é criado pela avó e pela mãe, entre a miséria e o sol. Mas é no seio dessa família pobre e semianalfabeta que Camus recebe suas primeiras lições sobre a morte: ela não é vista como algo sagrado ou misterioso. A avó vira muitos morrerem ao redor dela, dois filhos pequenos, o marido, o genro e todos os sobrinhos na guerra. A morte se tornara para ela tão familiar quanto o trabalho e a pobreza, era preciso pensar nas necessidades do presente e enfrentá-la como uma prova. Essa era também a realidade de todo o povo argelino, privados dessa devoção funerária que floresce nas civilizações. Em "L'Ironie" o menino narra a morte da avó: ele chora no enterro somente porque vê os outros chorarem e teme não ser sincero diante da morte. Esse tema será recuperado em L'Étranger: Meursault é julgado e condenado por sua indiferença no enterro da própria mãe. Os primeiros textos que Camus escreve bebem da fonte de sua experiência pessoal: e tem como figuras centrais a relação com essa avó e a mãe. ${ }^{26}$

O pai, portanto, será uma figura ausente nos escritos de Camus. Ele aparecerá somente em breves alusões, o que se conservara dele é apenas um pedaço do que fora sua morte e não sua vida: um quadro dourado com a cruz de guerra e a medalha militar, e o pequeno estilhaço da bomba que o matara. Nenhuma memória acerca deste homem:

Elle [la mère] le disait et le croyait, mais sans plus penser à son mari, maintenant oublié, et avec lui le malheur d'autrefois. Et plus rien ne restait, ni en elle ni dans cette maison, de cet homme dévoré par un feu universel et dont il ne restait qu'un souvenir impalpable comme les cendres d'une aile de papillon brûlée dans un incendie de forêt (CAMUS, 2008, p. 85).

Mais uma vez a pobreza tem aqui um papel fundamental: a memória dos pobres é menos nutrida que a dos ricos, para suportar a vida era preciso não se lembrar e viver no presente. Ninguém em sua casa era capaz de explicar suas origens, assim como todos em seu país, homens e mulheres nascidos em uma terra sem antepassados e sem memória, onde o aniquilamento daquele que os precederam fora quase total.

No entanto, no ano de 1951, encontramos uma nota que colocará o pai e a sua morte como o centro de uma nova narrativa: "Com 35 anos o filho vai ao túmulo do pai e percebe que esse morreu com 30 anos. Ele se tornou o mais velho" (CAMUS, 1985, p. 27-28). Em 1953, as notas abundam: "Procura do pai ou o pai desconhecido", seguem-se planos para a narrativa. São as ideias para Le Premier Homme que estão se delineando.

\footnotetext{
${ }^{26}$ Em prefácio para a reedição de L'Envers et L'Endroit, em 1958, dois anos antes de sua morte, Camus identifica as imagens e temas centrais de sua obra: "uma velha mulher, uma mãe silenciosa, a pobreza, a luz sobre as oliveiras da Itália, o amor solitário e povoado, tudo o que testemunha, aos meus olhos, a verdade” (CAMUS, 2006, p. 36).
} 
"Procura do pai" será a primeira parte da narrativa. O narrador relata que nada sabia deste pai morto na batalha do Marne, em 1914, a não ser detalhes do que tinha descoberto através do silêncio de sua mãe. ${ }^{27}$ Aos 40 anos, ele se dirige a Saint-Brieuc para visitar o túmulo do pai. Ele, que até então experimentara uma indiferença por esse homem desconhecido, queria saber quem aquele fora homem, ele lhe parecia agora mais próximo do que qualquer outra pessoa do mundo. São os rastros de seu pai que ele tentará encontrar no capítulo "O pai. Sua morte. A guerra. O atentado.", e não encontrará mais que simples vestígios da passagem desse homem pela terra: algumas parcas lembranças da mãe e as curtas cartas enviadas do front. O que ele encontra, porém, com essa busca é a evidência mais completa da existência desse homem: "O filho ou o Primeiro Homem." será a segunda parte do romance, onde ele reencontrará a infância e a si mesmo.

Oh! oui, c'était ainsi, la vie de cet enfant avait été ainsi [...] Oui, il avait vécu ainsi dans les jeux de la mer, du vent, de la rue, sous le poids de l'été et les lourdes pluies du bref hiver, sans père, sans tradition transmise, mais trouvant un père pendant un an, et juste au moment où il le fallait, et avançant à travers les êtres et les choses [...] la connaissance qui s'ouvrait à lui pour se fabriquer quelque chose qui ressemblait à une conduite et pour se créer sa propre tradition (CAMUS, 2008, p. 300).

E que tradição é essa senão aquela forjada pela própria escritura?

Em 1959, Camus se retira só para sua casa em Loumarrin, Le Premier Homme é sua prioridade absoluta. Em maio, ele escreve satisfeito em seu caderno: "Trabalho retomado. Eu avancei na primeira parte de Le Premier Homme" (CAMUS, 1989, p. 267). O tempo passa, dezembro se aproxima, e com ele as festas. A casa se encherá, a família virá de Paris e o trabalho será interrompido.

Em 6 de janeiro de 1960, Camus segue para Paris no carro da família Gallimard, enquanto sua esposa e seus filhos tomam o trem. O carro vai rápido, às $13 \mathrm{~h} 54$ precisamente, como mostra o relógio do painel, o Facel-Vega se projeta sobre uma árvore. Camus morre instantaneamente. Sua maleta é lançada para fora do carro, nela as 144 páginas do manuscrito, inacabado.

A morte está na origem e no fim dos escritos de Camus, como bem notou Sartre num artigo em sua homenagem: doença e acidente se relacionam ao absurdo. ${ }^{28}$ Mas a morte dessa vez faz calar a obra, interrompe a escritura. Em uma das notas escritas no final do manuscrito podemos ler: "O livro deve ser inacabado" (CAMUS, 2008, p. 333). Mas Camus não estava prevendo sua morte, essa forma de inacabamento teria sido proposital e não fruto de um triste acaso. As

\footnotetext{
${ }^{27}$ Ele conhecia apenas uma história sobre o pai, contada pela avó: ele fora ver uma execução capital e voltara lívido. Este fato será central para Jacques Cormery, assim como para Camus. Para o menino, essa história o havia impressionado, perseguindo-o em sonhos: vinham buscá-lo para ser executado. E durante muitos anos, vivera a mesma angústia do pai, essa era, portanto, a única herança evidente e certa que ele lhe deixara. A condenação à morte também foi um tema que perseguiu os escritos de Camus desenvolvendo-se principalmente em Réflexions sur la guillotine de 1957, texto que ele inicia pela evocação dessa memória pessoal. ${ }^{28}$ L'accident qui a tué Camus, je l'appelle scandale parce qu'il fait paraittre au cœur du monde humain l'absurdité de nos exigences les plus profondes. Camus, a vingt ans, brusquement frappé d'un mal qui bouleversait sa vie, a découvert l'absurde - imbécile négation de l'homme. Il s'y est fait, il a pensé son insupportable condition, il s'est tiré d'affaire. Et l'on croirait pourtant que ses premières œuvres seules disent la vérité de sa vie, puisque ce malade guéri est écrasé par une mort imprévisible et venue d'ailleurs (SARTRE, 1970, p. 172).
} 
notas e planos que encontramos no final do manuscrito, porém, não deixam dúvidas: Camus daria continuidade à história. Talvez fosse preciso ainda meses ou talvez anos para terminar o que se anunciava como sua maior obra, onde podemos ler o amor que Camus tinha por sua família, pela Argélia, pela vida.

" «Il n’y a pas d'amour de vivre sans désespoir de vivre ", ai-je écrit, non sans emphase, dans ces pages. Je ne savais pas à l'époque à quel point je disais vrai; je n'avais pas encore traversé les temps du vrai désespoir. Ces temps sont venus et ils ont pu tout détruire en moi, sauf justement l'appétit

désordonné de vivre. " Prefácio a L'Envers et L'Endroit, 1958.

\section{REFERÊNCIAS BIBLIOGRÁFICAS:}

CAMUS, Albert. Essais. Paris: Gallimard, Bibliothèque de la Pléiade, [1965], 2000. . Euvres Complètes I 1931-1944. Paris: Gallimard, Bibliothèque de la Pléiade, 2006. . Carnets I Mai 1935-Février 1942. Paris: Gallimard, 1962. . Carnets II Janvier 1942-Mars 1951. Paris: Gallimard, 1965. Le Premier Homme. Paris : Gallimard, coleção Folio, [1994], 2008.

GUÉRIN, Jeanyves (org.). Dictionnaire Albert Camus. Paris: Robert Laffont, coleção Bouquins, 2009.

LEBRAVE, Jean-Louis. «L'écriture inachevée», [En ligne], Mis en ligne le: 26 octobre 2007 Disponível em: http://www.item.ens.fr/index.php?id=187207

LÉVI-VALENSI, Jacqueline. Albert Camus ou la naissance d'un romancier. Paris: Gallimard, Les Cahiers de la NRF, 2006.

SARTRE, Jean-Paul. "Albert Camus”. In: Les Critiques de notre temps et Camus. Paris: Grenier, 1970. SCHOPENHAUER, Arthur. Metafísica do Amor Metafísica da Morte. São Paulo: Martins Fontes, 2004.

TODD, Olivier. Albert Camus: une vie. Paris: Gallimard, 1996.

VIALLANEIX, Alain. Le Premier Camus suivi de Écrits de jeunesse d'Albert Camus. Paris: NRF; Gallimard, 1973. (EJ).

VIRCONDELET, Alain. Albert Camus: fils d'Alger. Paris: Fayard, 2006. 